\title{
RESERVA ECOLÓGICA do IBGE - OPILIACEAE
}

Ronaldo Marquete ${ }^{1}$

\section{Resumo}

(Reserva Ecológica do IBGE - Opiliaceae) O trabalho trata da família Opiliaceae na áreada Reserva Ecológica do IBGE, situada em Brasília, Distrito Federal, com base na representatividade da família em coleções de herbários e observações de campo. Registrou-se para esta área apenas a ocorrência de Agonandra brasiliensis Miers ex Benth. \& Hook. f. subsp. brasiliensis. O estudo taxonômico consiste em descrições, comentários, material examinado, além de informações sobre a distribuição geográfica, habitat, floração e frutificação.

Palavras-chave: Opiliaceae, Agonandra, cerrado, flora, Brasília, Brasil

\section{Abstract}

(Ecological Reserve of IBGE - Opiliaceae) This work treats the family Opiliaceae in the area of the Ecological Reserve of IBGE, located in Brasília, Federal District, based on herbarium collections and field observations. It was detected for this area just one taxon Agonandra brasiliensis Miers ex Benth. \& Hook. f. subsp. brasiliensis. This taxonomic study consists of descriptions, comments, examined material, besides information about the geographical distribution, habitat, flowering and fruiting time.

Key-words: Opiliaceae, Agonandra, cerrado, flora, Brasilia, Brazil.

\section{INTRODUÇÃO}

Opiliaceae compreende 10 gêneros e 33 espécies. Apresenta distribuição pantropical, com nove gêneros no Velho Mundo e um na América tropical (Hiepko \& Gracie 2004). Alguns ocorrem na Ásia e Austrália, outros são restritos à África e Madagascar, tendo também os comuns a ambas as regiões.

Agonandra distribui-se do México até o norte da Argentina (Hiepko 2000). No Brasil ocorrem quatro espécies distribuídas em diferentes ecossistemas.

O trabalho apresentado visa ampliar o conhecimento florístico da Reserva. A família está representada na área apenas por Agonandra brasiliensis Miers ex Benth. \& Hook. subsp. brasiliensis, distribuída pelo cerrado, campo sujo e cerradão.

O estudo vem ressaltar a importância do conhecimento científico para fortalecer as bases da conservação e preservação da diversidade florística desta Reserva.

\section{Material e Métodos}

A Reserva Ecológica do IBGE, também conhecida pelo nome de Reserva Ecológica do Roncador - RECOR, faz limite com duas outras áreas de preservação: a do Jardim Botânico de Brasília e a da Universidade de Brasília, formando um trecho contínuo de mais de 7.000 ha destinados à pesquisa e à preservação da Biota.

Constitui-se em uma das Unidades de Conservação do cerrado, localizada no Planalto Central brasileiro a $33 \mathrm{~km}$ ao sul de Brasília, na Rodovia BR-251, nas coordenadas $15^{\circ} 56^{\prime} 41^{\prime \prime S}$ e $47^{\circ} 53^{\prime} 07^{\prime \prime W}$ GRW. A área tem ca. 1.360 ha com altitude que varia de 1.048 a $1.160 \mathrm{~m}$, relevo suave e típico de chapadas e desníveis representados apenas pelos vãos da rede de drenagem. Os solos predominantes são os latossolos vermelho-amarelos, além de porções significativas de latossolo vermelhoescuro, cambissolos e solos orgânicos, podzólicos, petroplinticos e gleyzados (Pereira et al. 1989 e 1993).

Artigo recebido em 09/2004. Aceito para publicação em 05/2005.

${ }^{1}$ Fundação Instituto Brasileiro de Geografia e Estatística - IBGE. Instituto de Pesquisas do Jardim Botânico do Rio de Janeiro, Rua Pacheco Leão 915, Jardim Botânico, Rio de Janeiro, RJ, CEP 22460-030. e-mail: rmarquet@jbrj.gov.br 
A Reserva apresenta os principais tipos de vegetação do planalto central como cerradão, cerrado, campos (sujo e limpo), matas de galeria e veredas (Ribeiro \& Walter 1998).

As atividades de campo na Reserva Ecológica do IBGE foram realizadas entre 1997 e 1998, para observações do representante da família em seu ambiente, bem como coleta de material botânico em vários pontos de amostragem. O material foi incluído no acervo do herbário do IBGE, com duplicatas no herbário do Jardim Botânico do Rio de Janeiro (RB). O estudo taxonômico foi realizado em coleções herborizadas através de análise morfológica e de bibliografia especializada. São fornecidos os dados referentes a floração e frutificação, freqüência, distribuição geográfica, habitat e nomes populares. A descrição, observação e ilustração foram realizadas apenas com base no material ocorrente na área. Para confeccionar as ilustrações utilizou-se o estereomicroscópio equipado com câmara clara. Foi acrescentado material adicional complementar à distribuição geográfica e às análises complementares, principalmente referentes aos frutos e às flores.

\section{Resultados}

Na Reserva, Opiliaceae está representada por apenas uma espécie, que apresenta diversos indivíduos femininos distribuídos pelas faciações do cerrado, sendo somente um exemplar masculino localizado em cerrado alto. Entre os exemplares estudados, a maior dificuldade para identificação dos indivíduos masculinos, foi devido à presença de um disco diferenciado e do grande dimorfismo foliar.

O gênero é composto de árvores, dióicas, com ramos cilíndricos, não lenticelados. Folhas persistentes a caducas no período seco, alternas, inteiras, simples, peninérveas, lanceolado-ovadas a lanceoladas; pecíolos finos, flexuosos; sem estípulas. Inflorescências axilares, multifloras; brácteas diminutas; pedicelos não articulados; flores actinomorfas, tépalas persistentes; flores masculinas com estames de filetes cilíndricos, anteras rimosas; ovário rudimentar; flores femininas sem estames, ovário súpero; estilete séssil; estigma crasso.

Agonandra brasiliensis Miers ex Benth. \& Hook. f. subsp. brasiliensis, Gen. pl. 1(1): 349.1862; Engler in Martius, Flora brasiliensis, 12(2): 37-38. 1872; Hiepko in Görts-van Rijn, Flora Guianas, Ser. A, 14: 36. 1993; Hiepko, Flora Neotropica Monograph 82: 53.2000; Groppo Jr. \& Pirani, Boletim de Botânica da Universidade de São Paulo 21(2): 279. 2003.

Tipo: Brasil.Ceará: Villa do Crato, out.1938 (flor masculina), Gardner 1503 (lectótipo K, foto RB!; Isolectótipo BM, G NY; Paralectótipo: Brasil. Piauí: agosto 1839 (flor masculina), Gardner 2506 (BM, K, NY, foto RB!).

Agonandra duckei Huber ex Ducke, Bol. Mus. Paraense Hist. Nat. 7: 108. 1913. Agonandra granatensis Rusby, Descr. S. Amer. Pl.14. 1920.

Agonandra lacera Toledo, Arq. Bot. Estado de São Paulo Nov. Ser. 3(1): 14, tab. 4. 1952. Agonandra macedoi Toledo, Arq. Bot. Estado de São Paulo Nov. Ser. 3(1): 13, tab. 3. 1952. Figuras 1, 2 e 3.

Árvore pequena a grande, 2-5 (-13) m alt. Tronco com casca fissurada, corticosa, acinzentada; ramos glabros, acinzentados. Folhas com pecíolo glabro, decurrente, semicilíndrico até próximo a lâmina, $1,8-2,3 \mathrm{~cm}$ compr.;lâmina 4,5-9cm x 2-3 cm, ápice caudado, base cuneada a curtamente atenuada, bordo inteiro, semicrassa, coriácea a cartácea, discolor verde, glabra, 4 nervuras secundárias ascendentes, reticulação das veias e vênulas densa, mais proeminentes na face abaxial. Inflorescência racemosa, 3-5 cm compr. Flores masculinas com aroma adocicado; tricomas glândulosos; pedúnculo 0,8-1,6 cm compr., cilíndrico; brácteas côncavas, triangulares, tricomas diminutos glândulosos facilmente vistos na inflorescência com botões; pedicelos ca. $1 \mathrm{~mm}$ compr., cilíndrico, botões globosos, tricomas diminutos, glânduloso, tépalas 5, inconspícuas, ca. 2,5 mm compr., oblonga a oblongolanceolada, ápice agudo, livres, persistentes, esverdeadas, pilosas; estames 5, filetes 2-2,5 
$\mathrm{mm}$ compr., glabros; anteras oblongas, sem glândula apical; lobos do disco ca. 1,2 mm compr., carnosos, ornados, esverdeados, glabros; ovário nulo. Flores femininas com tricomas diminutos glândulosos; pedúnculo 1$3 \mathrm{~cm}$ compr., cilíndrico; brácteas caducas, diminutas, oblongas, pedicelos 1-2 mm compr., cilíndricos; botões oblongos, tricomas diminutos glândulosos; tépalas 5, inconspícuas, 2-2,5 mm compr., oblongas a oblongo-lanceoladas, caducas, esverdeadas, ápice agudo; estames nulos; ovário ovado, crasso, discóide, inteiro. Fruto drupa, 1,7-2,4 x 1,5-1,9 cm, globosa a oblonga-eliptica, verde, glabra, mesocarpo carnoso, endocarpo coriáceo a lenhoso, castanho/amarelado; sementes $1 \mathrm{~cm}$ x $0,8 \mathrm{~cm}$, globosas, alongadas, castanhas; embrião ca. 7 mm compr., fusiforme; tépalas persistentes no fruto ainda jovem.

Material Examinado: BRASIL. DISTRITO FEDERAL: Brasília, RECOR, 03.XI.1999, bt., D. Alvarenga 1280 (IBGE, RB); 22.V.1997, fl. fem., R. Marquete \& M. L. Fonseca 2799, 2802, 2803 (IBGE, RB); 02.IX.1998, bt. e fl. masc., R. Marquete 2947 (IBGE, RB); 03.IX.1998, bt. e fl. fem., $R$. Marquete 2956, 2957, 2958, 2960, 2962, 2963 (IBGE, RB). Material adicional examinado: BRASIL. Ign., s/d, E. Warming 687 (C); Ign., s/d, Glaziou 11587 (C); PARÁ: Monte Alegre, 11.XII.1908, fr., A. Ducke 9870 (RB,MG); 17.XII.1908, fr., A. Ducke 9908 (RB, MG); 8.IX.1916, bt. e fl., A. Ducke 16514 (RB, MG); Faro, 07.X.1915, fr., A. Ducke s.n. (RB 8512, MG); 26.I.1910, A. Ducke 10552 (RB, MG); Alto Arirambo, Trombetas, 08.X.1913, bt., A. Ducke 14932 (RB, MG); Bragança, 10.I.1923, fl., A. Ducke s/ $n^{\circ}$ (RB:18.148); Santarém, 05.X.1962, fl. e fr., A. P. Duarte 7330 (RB, F, NY); MATO GROSSO: 1249'S

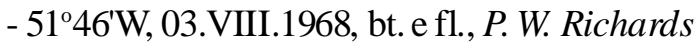
6583 (RB, K); Cristópolis, arredores, 25.X.1995, Hatschbach et al. 63884, (C); Serra do Espigão Mestre, 06.IX.1978, bt. e fl., J. P. S. Lima 116 (RB, HRB); próx. ao Rio Coxipó, 14.IV.1978, E. Mileski 039 (RB, HRB); 15³2'S - 56 $08^{\prime} \mathrm{W}$ (folha SD. 21 - ZC), 10.XI.1977, fr.,


Figura 1 - Agonandra brasiliensis Miers ex Benth. \& Hook. f. subsp. brasiliensis. a. flor masculina; b. flor feminina; c. detalhe das folhas e suas diferentes formas.

J. M. Lemos 4060 (RB,HRB); GOIÁS: Ign., Glaziou 20843, s/d (C); Parque Ecológico da Terra Ronca/Morro das Cabras, 19.X.1994, fr., Alfeu/Sebastião 05 (RB, IBGE); São Miguel do Araguaia, Luiz Alves, 26.VIII.1996, bt. e fl., $S$. S. Silva 37 et al. (RB); Cristalina, 11.V.1997, B. A. S. Pereira, \& D. Alvarenga 3390 (RB, IBGE); Padre Bernardo, 12.VI.2002, bt. e fl., M. L. Fonseca et al. 3464 (IBGE, RB); Luziânia, 18.VI.1980, E. P. Heringer 17859 (IBGE, RB); BRASÍLIA (DF): X.1964, bt. e fl., G. M. Barroso 657 (RB); 02.VIII.1977, bt., E. P. Heringer 16.745 (RB, UB); estr. Planaltina/PADF, Rod.DF-130. Bacia do São Bartolomeu, 13.V.1998, R. Marquete \& D. Alvarenga 2898 (IBGE, RB); Córrego Forquilha, 13.V.1998, bt. e fl., R. Marquete \& D. Alvarenga 2894 (IBGE, RB); MATO 
GROSSO DO SUL: Próx. à Aldeia São João, 07.XI.1980, fr., J. G. Guimarães 1268 (RB, HRB); MARANHÃO Barra do Corda, 20.VII.1909, bt. e fl., M. Arrojado Lisbôa 2466 (RB, MG); 17.VIII.1909, bt.,fl. e fr., $M$. Arrojado Lisbôa 2342 (RB, MG); São Luiz do Maranhão, 10.IX.1903, fl., A. Ducke 357 (RB: 8513, MG); PIAUÍ: Lagoa do Mato, s/d, Lützelburg 1762 (RB); Piracuruca, PARNA Sete Cidades, 13.IX.1977, fl. efr., G. M. Barroso \& E. F. Guimarães 28 (CCN, RB); 14.IX.1977, bt., G. M. Barroso \& E. F. Guimarães 151 (RB); 16.IX.1977, fl. e fr., G. M. Barroso 267 (RB, CCN); Morro de Picos, Faz. Palmas,
21.IX.1973, fl. e fr., F. B. Ramalho, 261 (RB); CEARÁ: Serra de Ibiapaba, prov. do Jacaré, 15.X.1909, fl., M. Arrojado Lisboa s $/ n^{\circ}$ (RB: 10673, MG); Serra do Baturité, 05.XI.1939, fl., J. Eugenio 517 (RB); BAHIA: Barreiras, 21.XI.1980, fr., S. B. Silva 164 (RB, HRB); Santa Rita de Cássia, 27.VIII.1980, fl., Santino 289 (RB, HRB); Cocos, Faz. Trijunção, 16.V.2001, fl., R. C. Mendonça 4292 (IBGE, RB); Formosa do Rio Preto, 11.XI.1997, fr., R. C. Mendonça 3274 (IBGE, RB); MINAS GERAIS: Pirapora, 18.XI.1955 fr., M. Magalhães 6504 (RB); Paraopeba, 18.IX.1956, fl., E. P. Heringer s.n. (RB 97314, PMG); Arinos,



Figura 2 - Agonandra brasiliensis Miers ex Benth. \& Hook. f. subsp. brasiliensis. a. fruto; b. fruto em corte transversal; c. fruto em corte longitudinal; d. corte longitudinal da semente mostrando embrião e e. detalhe da forma do embrião. 

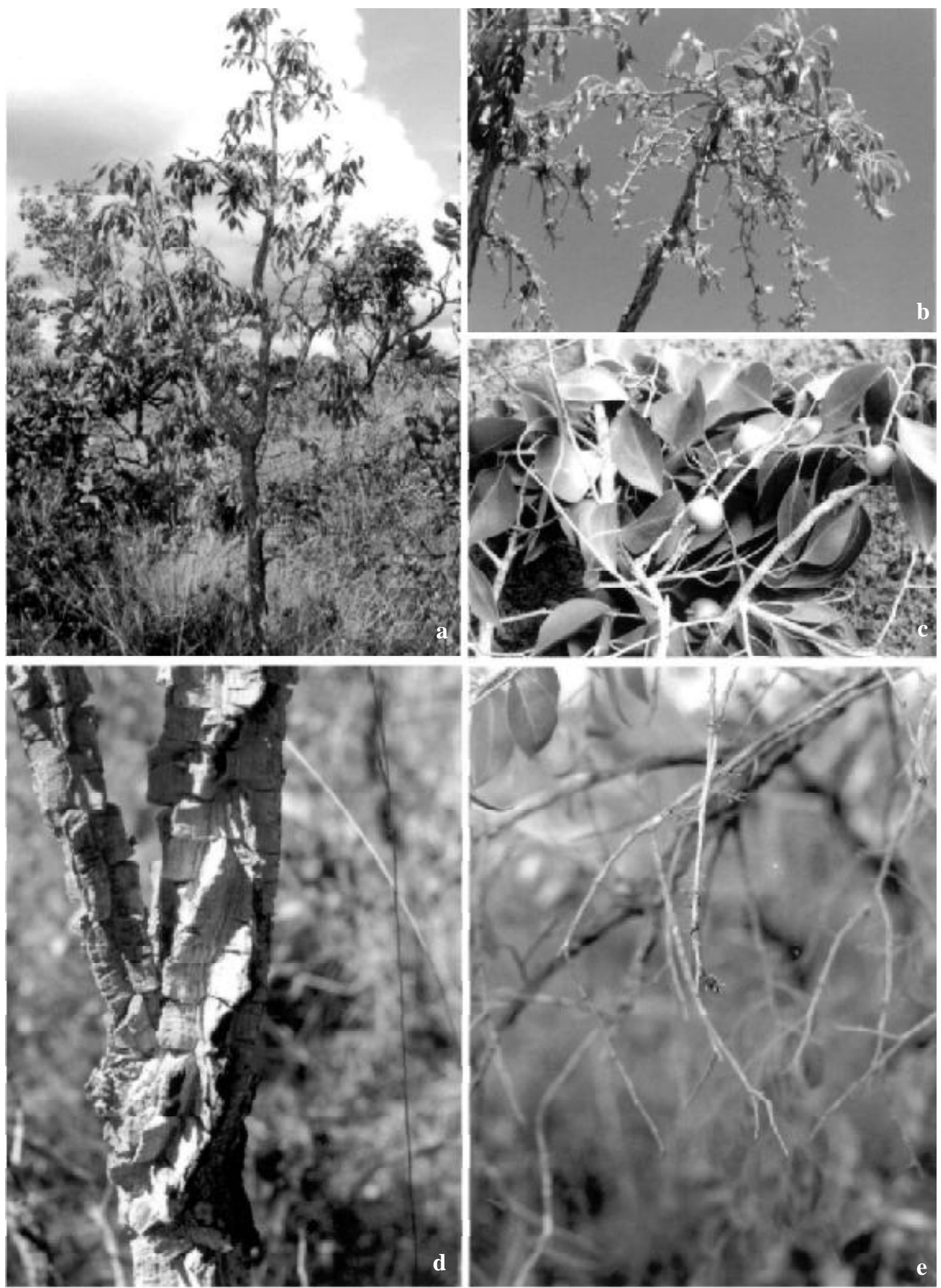

Figura 3 - Agonandra brasiliensis Miers ex Benth. \& Hook. f. subsp. brasiliensis. a. hábito; b. detalhe da inflorescência masculina; c. detalhe dos ramos com frutos; d. tronco com casca corticosa; e. detalhe dos ramos com inflorescência de flores femininas. 
22.X.1995, fr., B. A. S. Pereira \& D. Alvarenga 2931 (IBGE, RB); Formoso. PARNA Grande Sertão Veredas, 26.X.1997, fr., D. Alvarenga 1020, (IBGE, RB); ESPÍRITO SANTO: Linhares, Reserva Floresta da CVRD, 20.I.1994, fr., D. A. Folli 2183 (RB, CVRD). PARAGUAI. Ign., s/d, E. Hassler 7247 (C); SAN PEDRO: Alto Paraguai, Primavera, $A$. Woolston 743, 02.X.1956 (C); 30.IV.1954, A. Woolston 1329 (C).

Distribuição geográfica e habitat: A espécie ocorre no Panamá, Guiana, Venezuela, Colômbia, Bolívia, Brasil (Acre, Roraima, Pará, Mato Grosso, Goiás, Distrito Federal, Maranhão, Piauí, Ceará, Bahia, Minas Gerais eSão Paulo), Argentina e Paraguai. Na área em estudo, ocorre em mata ciliar, cerrado denso (savana florestada), campo cerrado aberto (savana parque) e campo cerrado (savana arborizada, fig. 3a). Como observado em sua distribuição, o táxon atinge outros tipos de vegetação no território brasileiro como carrasco, caatinga (savana estépica), área de campo pedregoso na transição campo rupestre - cerrado (Groppo Jr. \& Pirani 2003) e floresta estacional semidecídual.

Nome Vulgar: DF. RECOR - pau-marfim; PA - pau-marfim, pau-marfim-do-pará, paumarfim-do-cerrado; MT - marfim, pau-d'alhodo-cerrado; GO - pau-marfim, marfim-deespinho; MS - cagaita; MA - pau-marfim, paumarfim-do-campo, cerveja-de-pobre, paumarfim-da-mata; PI - pao-marfim, marfim, pau-marfim;CE - pau-marfim; BA - marfim, pau-marfim; MG - imbu-d'anta, quina-deveado, cerveja-de-pobre.

Floração e Frutificação: Nas observações em campo e de coleções de herbários, verificou-se que a espécie começa a florescer em maio, quando manifesta a presença dos primeiro botões, porém a floração intensa ocorre de agosto a dezembro, podendo esporadicamente chegar a janeiro. Já seus frutos começam em agosto alcançando dezembro, sendo mais raros em janeiro.

Importância Econômica: A madeira é utilizada em marcenaria, carpintaria e como lenha, em construção provisória no meio rural e em confecção de cabos de ferramenta. A cortiça que reveste o tronco e os galhos é considerada de boa qualidade, tendo sido objeto de aproveitamento industrial, em mistura com outras espécies regionais.

A casca e as raízes, em infusão na água, dão origem a uma solução de cor e sabor similares ao da cerveja, à qual se atribuem propriedades diuréticas. Da casca obtém-se uma tintura amarelada, usada no tingimento artesanal de tecidos e no tratamento de ulcerações da pele. Morcegos, aves, macacos e animais terrestres alimentam-se dos frutos, que são eventualmente aproveitados pelo homem. As sementes fornecem um óleo amarelado, com ponto de congelamento muito baixo $\left(-20^{\circ} \mathrm{C}\right)$, usado no meio rural como cicatrizante de feridas (Camargos et al. 2001; Pereira 2002).

Comentários: O lectótipo foi designado por Hiepko (1993), que excluiu os materiais sintipos Gardner 1519 e Pohl 1721 por pertencerem a Agonandra excelsa Griseb.

Os binômios Agonandra lacera Toledo e Agonandra macedoi Toledo foram estabelecidos como sinônimos por Hiepko (2000), com o que se concorda.

Segundo Padilha (1977), este táxon apresenta distribuição ampla no neotrópico, o que se confirma com base em estudos bibliográficos e levantamento de material examinado.

\section{Conclusão}

Os resultados obtidos na pesquisa revelam que o táxon tem ampla distribuição desde o Panamá até o Paraguai, sendo mais frequiente em vegetação de savana (cerrado).

A espécie apresenta hábito arbustivo a arbóreo, sendo o arbustivo (2-4 m) predominante em áreas de savana aberta e o arbóreo de médio porte em savana arborizada (cerrado, fig. 3a). Nesta vegetação há um grande número de exemplares que variam no seu porte, atingindo cerca de 6 metros. Quando na proximidade das áreas de floresta de galeria, florestas ciliares, savana florestada 
(cerradão) ou floresta seca, o hábito pode ser arbóreo, alcançando até 10 metros altura (raros $13 \mathrm{~m}$ ). Sempre apresenta tronco com casca corticosa e fissurada (fig. 3d), e suas folhas caducas tem grande dimorfismo nos períodos mais secos.

De acordo com as coleções examinadas, o táxon pode ser considerado protegido devido a sua presença em várias Unidades de Conservação.

\section{Agradecimentos}

Ao Instituto Brasileiro de Geografia e Estatística (IBGE), em especial à Profa. Roberta C. Mendonça, sua equipe e demais funcionários da Reserva Ecológica do IBGE - Brasília, pelo apoio concedido. Ao Instituto de Pesquisas Jardim Botânico do Rio de Janeiro pelas instalações concedidas na área de Botânica Sistemática para realização deste trabalho. Aos curadores dos herbários IBGE, $\mathrm{RB}, \mathrm{K}$ e C, pelo acesso ao material botânico, imprescindível para a realização deste trabalho, bem como pela gentileza no atendimento. Às professoras Dra. Angela Maria S. da Fonseca Vaz, Dra. Nilda Marquete F. da Silva e Dra. Rafaela C. Forzza pela orientação, companheirismo, apoio e valiosas sugestões no texto.

\section{REFERÊNCIAS B IBLIOG RÁFICAS}

Camargos, J. A. A.; Coradin, V. T. R.; Czarneski, C. M.; Oliveira, D de \& Meguerditchian, I. 2001. Catálogo de Árvores do Brasil, Instituto Brasileiro do Meio Ambiente e dos Recursos Naturais Renováveis, Laboratório de Produtos Florestais. Brasília. Ed. IBAMA, 896p.

Engler, A. 1872. Olacineae. In: C. F. P. Martius, Eichler (eds). Flora brasiliensis. Munchen, Wien, Lipsiae, Frid. Fleischer, vol. 12, pars.2, p.1-39, t. 1-8.

Groppo Jr., M. \& Pirani, J. R. 2003. Flora da Serra do Cipó, Minas Gerais: Opiliaceae.
Boletim de Botânica da Universidade de São Paulo 21(2):279-281.

Hiepko, P. 1993. Opiliaceae. In: A. R. A. Görts-Van Rijn (Ed.), Flora of the Guianas, Ser. A, 14:36-39. Koeltz Scientific, Koenigstein.

Hiepko, P. 2000. Opiliaceae. Flora Neotropica Monograph 82:1-53.il.

Hiepko, P. \& Gracie, C. 2004. Opiliaceae. In:Smith, N., Mori, S. A., Henderson, A., Stevenson, D. Wm. \& Heald, S. V. (eds.). Flowering plants of the Neotrpics. New York, The New York Botanical Garden, Princeton University Press, pp. 281-282.

Padilha, M. R. da S. 1977. Sobre a dispersão geográfica de espécies brasileiras de Opiliaceae. Leandra 6-7(7):119-125.

Pereira, B. A. da S. 2002. Árvores do Brasil Central. Espécies da região geoeconômica do Distrito Federal. IBGE, Diretoria de Geociências - Rio de Janeiro: IBGE, v. 1: 265-268. il.

Pereira, B. A. da S., Furtado, P. P., Mendonça, R. C. de \& Rocha, G. I. 1989. Reserva Ecológica do IBGE (Brasília, DF): Aspectos históricos e fisiográficos. Boletim da FBCN. RJ. 24: 30-43.

Pereira, B. A. da S., Aparecida da Silva, M. \& Mendonça, R. C. 1993. Reserva Ecológica do IBGE, Brasília (DF): Lista das plantas vasculares. Rio de Janeiro; IBGE, Divisão de Geociências do Distrito Federal. 43p. il.

Ribeiro, J. F. \& Walter, B. M. T. 1998. Fitofisionomias do Bioma Cerrado In: Sano, S. M. \& Almeida, S. P. Cerrado Ambiente e Flora 89-152.

Toledo, J. F. 1952. Species Brasilienses Agonandrae Miers. Arquivo de Botânica do Estado de São Paulo Nova Série 3 (1): 11-17. il. 

